\title{
Association among multimorbidity, physical disability and depression trajectories: a study of urban-rural differences in China
}

\author{
Chaoyang Yan ${ }^{1} \cdot$ Hui Liao $^{1} \cdot$ Ying Ma ${ }^{1} \cdot$ Qin Xiang ${ }^{1}$. Jing Wang ${ }^{1,2,3}$
}

Accepted: 19 February 2021 / Published online: 6 March 2021

(c) The Author(s) 2021

\begin{abstract}
Purpose The purpose of this study was to analyse the trajectories of depression in urban and rural areas, and to analyse the relationship among multimorbidity, disability and other variables and trajectories.

Methods Data from the China Health and Retirement Longitudinal Study were used. A latent class growth model was used to characterise the trajectories of urban and rural depression symptoms. Chi-square test was used to test the differences in respondents' characteristics among depression trajectories groups within urban and rural areas. The relationships among multimorbidity, disability and depression symptom trajectories were analysed via multinomial logistic regression.

Results Urban and rural depression trajectories were divided into three categories. Respondents in urban areas were divided into rising, remaining-low and declining group, and those in rural areas were divided into rising, remaining-low and remaining-high group. The depression scores of respondents with multimorbidity were more likely to rise, and this result was similar for the disabled respondents. Respondents who need help on activities of daily living and instrumental activities of daily living in urban areas were more likely to decline in depression scores. In rural areas, however, the values were consistently high. In urban and rural areas, the relationships among marital status, education and age and depression trajectories were different. Conclusions The depression trajectories are different in urban and rural China. Improving the quality of medical services, promoting the distribution of rural social resources and implementing more recreational activities could be beneficial for the promotion of mental health in rural areas.
\end{abstract}

Keywords Multimorbidity $\cdot$ Physical disability $\cdot$ Trajectory $\cdot$ Depression

\section{Introduction}

Depression is very common and has become a growing public health concern, affecting more than 300 million people of all ages and causing up to 43.1 million all-age disabilityadjusted life years (DALYs) [1,2]. The overall estimation of

Jing Wang

jingwang@ hust.edu.cn

1 Department of Health Management, School of Medicine and Health Management, Tongji Medical College, Huazhong University of Science and Technology, Wuhan 430030, Hubei, China

2 The Key Research Institute of Humanities and Social Science of Hubei Province, Huazhong University of Science and Technology, Wuhan 430030, Hubei, China

3 Institute for Poverty Reduction and Development, Huazhong University of Science and Technology, Wuhan 430030, Hubei, China current, 12-month and lifetime prevalence of major depressive disorder in China is $1.6 \%, 2.3 \%$ and $3.3 \%$, respectively [3]. A meta-study indicated that the pooled prevalence of depression symptoms was $23.6 \%$ (95\% confidence interval 20.3-27.2\%) among the elderly in China [4].

Research on depression is primarily concerned with influencing factors, prevention, treatment and financial burden. A 'U'-shaped curve was demonstrated between body mass index and post-stroke depression in patients aged less than 65 years [5]. The relationship between juvenile delinquency and adult depression was also investigated. Opie et al. focused on the relationship between dietary patterns and specific dietary factors and the prevention of depression [6]. Pastoor et al. have discussed medications for depression [7]. Cuijpers et al. pointed out that psychotherapy is effective in the primary care of depression and has a more lasting effect than drugs [8]. Greenberg et al. illustrated that the economic burden of patients with major depressive disorder in the United States increased by $21.5 \%$, and the composition 
of these costs remained stable, with about $45 \%$ attributed to direct expenses [9]. Due to the differences in China's urban and rural economic development level, household registration system design and employment types (rural population is mainly engaged in agricultural activities, while urban population is mainly engaged in industry and service), there are great differences in income, social resource allocation and access to welfare policies between urban and rural areas [10-12]. In 2018, the per capita disposable income of urban residents in China was 39,251 yuan, and that of rural residents was 14,617 yuan, which is a large gap. In 2015, 47.1\% of the rural population in China had an education level of primary school or below, which was much higher than the $13.1 \%$ in urban $[13,14]$.

Many studies have also been performed regarding the trends in depression. The incidence of depression increased by $49.86 \%$ from 1990 to 2017 worldwide [15]. From 1990 to 2017, in China, the all-age prevalence rate of depression per 100,000 rose from 3224.6 (95\% uncertainty interval (UI): 2976.6-3509.1) to 3990.5 (95\% UI: 3667.8-4353.0) [16]. The DALYs caused by depression in China is estimated to increase by about $10 \%$ from 2013 to 2025 [17]. Hence, the depression symptoms of the population may change over a period of time.

Several studies have paid attention to the trajectory of depression and its influencing factors. Saunders et al. analysed the trajectory category of depression and anxiety symptoms during psychotherapy and the baseline patient characteristics related to the trajectory [18]. Leung et al. analysed the relationship between chronic disease at baseline and the trajectory of depression [19]. Studies should also compare the trajectories of depression symptoms over time among different populations and analyse the relevant factors.

The trajectory of depression in urban and rural areas in China may be different because the prevalence of depression and the allocation of social resources vary between them. Zhang et al. pointed out that the prevalence of depression among the elderly in rural areas (29.2\%) is significantly higher than that of the urban population in China (20.5\%) [20]. Huo et al. described evident differences between urban and rural welfare systems in China [21]. Liu et al. explained that urban areas have more government support than rural areas in China [22]. Chen et al. demonstrated the differences in the distribution of health resources between urban and rural areas in China [23].

Physical health status, including multimorbidity and physical disability, can be tightly related to the trend of depression. According to a survey conducted among 5296 participants in East China, those with multiple chronic diseases were likely to have a depression symptom [24]. In addition, a British study showed that concurrent sensory disorders are associated with a low quality of life and high risk of depression symptoms [25]. Beck's model of depression development suggests that depression symptoms include a negative self-interpretation of an individual's multiple comorbidities [26]. Quality of life is a multi-dimensional concept. The study focused on the relationship between physical and mental health dimensions and took into account time changes, which has important implications for dynamic interventions to improve quality of life.

Additionally, socioeconomic status (SES) may affect the changes in depression. Women are more likely to have depression than men [27, 28]. Age is also associated with depression symptoms [29]. Meanwhile, married people have better mental health than those who are single, widowed, separated and divorced [30]. Low levels of education and income are risk factors for depression [31]. The relationship between working hours and depression has also been previously demonstrated [32]. Compared with living with a spouse alone, individuals living with a spouse and a child or those living alone were more likely to have depression symptoms [33]. Among psychiatric patients, smoking is associated with severe symptoms of depression and anxiety and with slow recovery but only in the case of nicotine-dependent smokers. A J-shaped relationship has been confirmed between alcohol consumption and depression among elderly people in South Korea [34].

Considering the factors related to depression symptoms can probably influence the depression development trend. The kinds of factors associated with the trajectory of depression development must be studied. Furthermore, remarkable differences exist in resource allocation and welfare system between urban and rural areas in China, and such differences can be closely related to depression prevention and control. Thus, a comparative study should be conducted on the trajectory of depression, especially, its influencing factors in urban and rural areas.

This study aimed to (1) explore the differences in depression trajectory between urban and rural areas in China with three-wave panel data; (2) find associated factors of the depression trajectory by analysing the relationship between physical health status, including multimorbidity and physical disability and other independent variables at baseline, and depression trajectories.

This study will be helpful to support depression prevention, and controlling dynamically. The research on the trajectory and influencing factors of depression in China, as the largest developing country in the world, can be meaningful to reveal the relationship between social resource allocation and mental health, especially for developing or underdeveloped areas of the world. 


\section{Methods}

\section{Data sources}

The data used in this study were obtained from China Health and Retirement Longitudinal Study (CHARLS), targeting the middle-aged and older population (45+ years), in China. CHARLS is an ongoing large-scale interdisciplinary investigation project sponsored by the National Development Research Institute of Peking University and jointly implemented by the Chinese Social Sciences investigation centre of Peking University and the Youth League Committee of Peking University, with surveys performed every 2 years from 2011 to 2015 .

CHARLS is sampled at the county-village-household-individual level through four stages. Specifically, in county-village sampling, CHARLS adopts probabilities that are proportional to size sampling. Based on the population of each district and county in 2009 and using regional, urban and rural areas and gross domestic product as stratified indicators, 150 counties (districts) were randomly selected in the whole country. Three villages (communities) were randomly selected from each of the 150 counties (districts) based on the permanent population of each village or community in 2009. A total of 450 villages (communities) were finally obtained. Exactly 80 households were randomly selected from the information list of all households in each sample village (communities).

The main household questionnaire of CHARLS contains information regarding basic demographics, health status, healthcare, employment and household economy (income, consumption and wealth). The national baseline survey of CHARLS was conducted between June 2011 and March 2012 on 17708 respondents. After excluding the depression missing data and samples that were lost to follow-up, 11,112 samples from three-wave panel data were analysed in this study (Fig. 1). Depression data were calculated in each wave, and multimorbidity, physical disabilities and SES and other independent data were all from wave 2011 as the baseline.

\section{Variables and definitions}

\section{Depression}

Depression was decided by the respondents' positive feelings, negative emotions and somatic symptoms in the CHARLS questionnaire. The 10-item Center for Epidemiologic Studies Depression Scale (CES-D10) was used to describe the depression symptoms, and the responses for CES-D10-based questionnaire were coded on a four-point

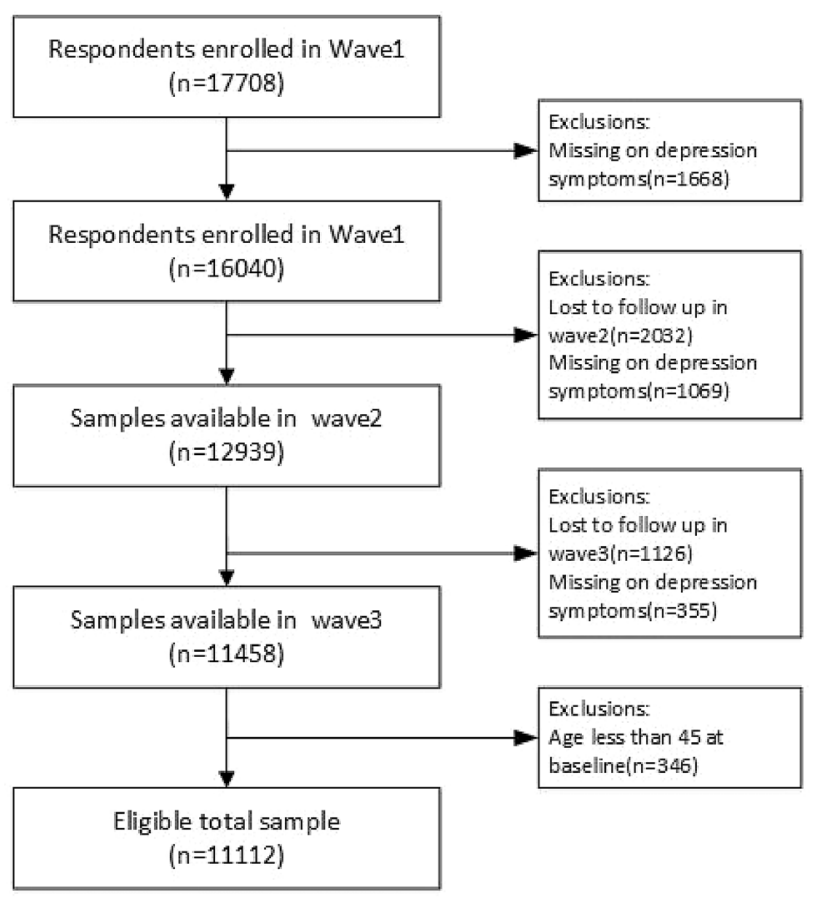

Fig. 1 Flowchart of sample selection

scale from 1 to 4 . Hence, the total scores for depression symptoms ranged between 10 and 40 , with 10 representing a perfect healthy mental status and 40 reflecting extremely severe depression. In this study, depression was used as a continuous variable based on the CES-D10 scores.

\section{Physical health status}

Respondents of CHARLS were asked to report chronic diseases since wave 2011. The fourteen kinds of chronic diseases should be diagnosed by doctors and ongoing for at least half a year. In this study, multimorbidity was defined as a binary variable. Thus, one group had one or none of the kinds of chronic diseases, and the other included two or more types of chronic diseases. Quality of life is a multidimensional concept. Its scope is larger than the state of physical health. However, physical health status is a part of quality of life. Our research focuses on reflecting quality of life through physical health status.

In this study, physical disability was evaluated based on activities of daily living (ADL) and instrumental activities of daily living (IADL). The CHARLS questionnaire in 2011 contained six ADL items (dressing, bathing, eating, getting into and out of bed and toileting, controlling urination and defecation) and five IADL items (preparing a hot meal, shopping for groceries, making telephone calls, taking medicines and managing money). Given that ADL and IADL represent different aspects of disability $[35,36]$, the 
study classified physical disability into four groups: neither ADL nor IADL needs help, only need help on IADL, only need help on ADL, both ADL and IADL need help.

\section{Other independent variables}

The SES variables analysed in this study included gender, age, marital status, education, occupation status, family income, living arrangement and lifestyle. Age was divided into four subgroups, namely, 45-49, 50-59, 60-69 and 70 years or above. This study defined marital status as a binary variable, implying that married couples who lived with their spouse or temporarily did not live together as having a spouse, whereas other marital conditions were treated as not having a spouse. Education in this study was divided into four levels: illiterate, primary school, junior high school and senior high school and above. Given that the respondents of CHARLS were mostly over 45 years old, we separated them into those who are still employed or engaged in workrelated activities from all the respondents as occupation status. Household income per capita was used to measure the economic status of the respondent's family, and quintile was used to show their economical level. Furthermore, based on whether the respondents lived in the same town or city as their children, the respondents' living arrangements were divided into two groups. In addition, smoking and drinking were included in the study and classified by lifestyle of smoking or drinking in the year before the survey. Table 1 provides the detailed coding of each variable.

\section{Statistical method}

The latent class growth model, which is a model used to describe the development feature of samples in a certain period and classify the development feature, was used to illustrate and classify the developmental trajectories of urban and rural depression symptoms in this study. Small values of Akaike Information Criterion (AIC), Bayesian Information Criterion (BIC) and adjusted Bayesian Information Criterion (aBIC) are preferred in selecting the number of latent classes [37]. After determining the trajectory groups, Chi-square analysis was used to test the differences in respondents' characteristics among depression trajectories groups within urban and rural areas. Then, multinomial logistic regression was used to explore the association between trajectories of depression symptoms and baseline multimorbidity, physical disability and other independent variables in urban and rural areas.

Mplus 8.0 was used to apply the latent class growth model, and STATA software 13 was used to execute the multinomial logistic regression and Chi-square analysis, with statistical significance at $p<0.05$.

\section{Ethical approval}

Ethical approval for data collection in CHARLS was obtained from the Biomedical Ethics Review Committee of Peking University (IRB00001052-11015). All interviewees gave written informed consent before recruitment to the study.

\section{Results}

Table 2 shows the model fitting results of the latent class growth model for depression symptoms. Panels A and B represent the model fitting results of urban and rural areas, respectively. We classified the trajectories of depression in urban and rural areas into three groups each, in accordance with the criteria including small values of BIC, aBIC and
Table 1 Coding of physical health status variables and other independent variables

\begin{tabular}{ll}
\hline Variable & Codes \\
\hline $\begin{array}{l}\text { Physical health status } \\
\text { Multimorbidity }\end{array}$ & $\begin{array}{l}1=\text { no, } 2=\text { yes } \\
1=\text { no limits, } 2=\text { only IADL, } 3=\text { only ADL, } 4=\text { both } \\
\text { Physical disability }\end{array}$ \\
$\begin{array}{l}\text { Other independent variables } \\
\text { Gender }\end{array}$ & $1=$ male, $2=$ female \\
Age (years) & $1=$ partnered, $2=$ single \\
Marital status & $1=$ illiteracy, $2=$ primary school, $3=$ junior high school, \\
Education & $4=$ senior high school and above \\
& $1=$ yes, $2=$ no \\
Occupation status & $1=$ worst, $5=$ best, from 1 to 5 is from the best to the worst \\
Family income & $1=$ yes, $2=$ no \\
Smoke & $1=$ yes, $2=$ no \\
Drink & $1=$ yes, $2=$ no \\
Living arrangement &
\end{tabular}


Fig. 2 The trajectory of depression symptom in urban and rural. a Urban trajectory, b rural trajectory

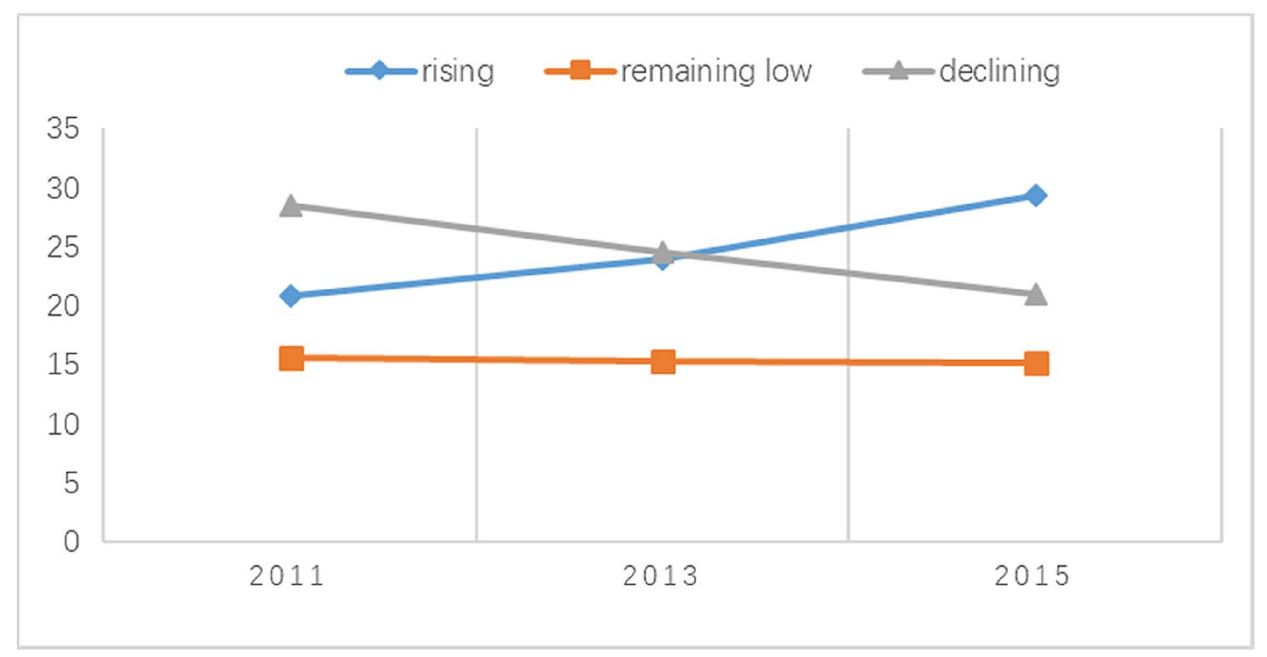

A Urban trajectory

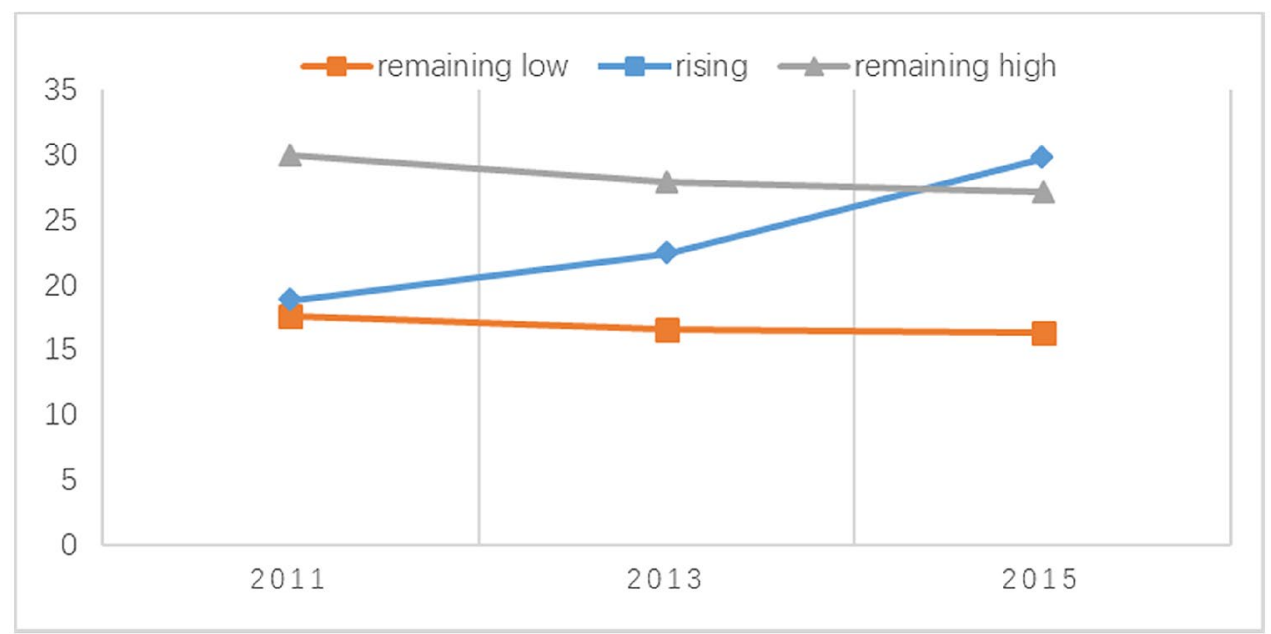

B Rural trajectory

\begin{tabular}{lllll}
\hline Class & AIC & BIC & aBIC & Entropy \\
\hline Panel A (Urban) & & & & \\
$2(n 1=83 \%, n 2=17 \%)$ & 72107.348 & 72176.508 & 72141.555 & 0.824 \\
$3(n 1=79 \%, n 2=11 \%, n 3=10 \%)$ & 71849.745 & 71937.767 & 71893.281 & 0.820 \\
$4(n 1=69 \%, n 2=13 \%, n 3=13 \%, n 4=5 \%)$ & 71521.075 & 71627.959 & 71573.941 & 0.812 \\
Panel B (rural) & & & & \\
$2(n 1=79 \%, n 2=21 \%)$ & 134036.208 & 134111.814 & 134076.859 & 0.774 \\
$3(n 1=77 \%, n 2=12 \%, n 3=11 \%)$ & 133792.552 & 133888.778 & 133844.289 & 0.774 \\
$4(n 1=63 \%, n 2=16 \%, n 3=14 \%, n 4=7 \%)$ & 133259.976 & 133376.823 & 133322.801 & 0.758 \\
\hline
\end{tabular}

Table 2 Model fit indices for longitudinal latent class analysis on CES-D10 over time in the sample may have been incorrectly indicated [38, 39]. Thus, three trajectory groups for urban and rural areas were the most acceptable. The rising and remaining-low groups of depression trajectory were observed in urban and rural areas. The main difference was the declining group in urban areas. However, the remaining-high group was observed in rural
AIC and an entropy score close to 1 [38]. According to the estimated posterior probabilities, the proportions of urban areas divided into three groups were $79 \%, 11 \%$ and $10 \%$, and those of rural areas were $77 \%, 12 \%$ and $11 \%$. Very small classes $(<10 \%$ of the total sample) may represent an accidental discovery, and hence, the number of potential classes 
areas based on the slope of depression score change. Therefore, the three groups in urban areas were rising, remaininglow and declining groups, whereas those in rural areas were rising, remaining-low and remaining-high groups (Fig. 2).

Table 3 shows the descriptive comparison of baseline characteristics within the urban and rural depression trajectory groups. Physical disability, multimorbidity, gender, marital status, education, family income, smoking and drinking were all significantly different among depression trajectories groups within urban and rural areas. Residential arrangement was not significant within urban and rural depression trajectories. Age and employment were only significant among depression trajectories group within urban areas. No disability, no multimorbidity, female, $50-59$ years old, partnered, primary school education, work participation, no smoking, no drinking and living with children were the most common characteristics in the baseline sample in urban and rural areas. The proportions of ADL and IADL in the urban declining group were slightly higher than that in the rising group. The proportion of multimorbidity and absence of spouse in the rural remaining-high group was higher than that in the rising group. Such finding can mean that physical function has a relationship with depression development.

Table 4 shows the results of multinomial logistic regression analysis between independent variables of baseline and depression trajectory groups within urban and rural areas. A common phenomenon, respondents with multimorbidity were more likely to increase in urban and rural areas, but those in rural locations were also more likely to retain high depression scores, given the rising trajectory group as reference. As for physical disability, with reference to the rising group, those who were physically disabled were more likely to show increased depression scores in urban and rural areas, and the scores of those who need help in ADL and IADL were more likely to continue to be higher in rural areas but may decrease in urban areas. These findings mean that physical function, including multimorbidity and physical disability, are risk factors for depression development in rural areas. The more chronic diseases and difficulties in ADL or IADL, the higher their risk to develop into highscore depression.

The association between gender and depression trajectories was consistent between urban and rural areas, that is, female's depression scores are more likely to rise than that of males. The association between age, marital status, education and depression trajectories differed between urban and rural areas. The CES-D10 scores of the respondents aged 50-59, 60-69 and >70 years from urban areas were more likely to remain low or decline compared with those aged 45-49 years, whereas this association was not significant for respondents from rural areas. The CES-D10 scores of respondents without spouse in rural areas were more likely to rise, whereas the scores were not significantly different between the single and partnered respondents in urban areas. Compared with the uneducated respondents, the CES-D10 scores of the rural respondents who were educated in primary school, junior school, senior school and above were more likely to be lower. Moreover, only the respondents in urban areas who were educated in junior school or senior school and above had significantly lower CES-D10 scores. These results imply that depression development is affected by different factors for urban and rural areas and is thus worthy of further discussion.

\section{Discussions}

In this study, although depression development was divided into three groups in urban and rural areas, trajectories between these locations are different. A significantly declining group was observed in urban areas but not in rural areas. Respondents with multimorbidity were more likely to increase for both urban and rural areas, and the respondents in rural locations were also more likely to retain high depression scores in comparison with the rising group. Similarly, those who were physically disabled in urban and rural area were more likely to achieve high CES-D10 scores. Respondents needing help in ADL and IADL in urban areas were more likely to have declining depression score, whereas the respondents in rural areas were more likely to retain high depression score. Additionally, the association between age, marital status, education and depression trajectories differed between urban and rural areas. Therefore, depression develops differently in urban and rural areas, and the related factors also vary.

The quality of life, uneven allocation of resources in urban and rural areas and social participation of respondents may be potential factors for the unparalleled depression trajectories in urban and rural areas.

The health level influenced by physical health status can be the main and direct reason for depression development. The adverse effects of multimorbidity and physical disability on the health level may increase the CESD10 scores of the responders [40]. Chronic disease is a condition in which a disease lasts for a prolonged period and is difficult to cure; the causes of chronic diseases are difficult to determine. This condition means that patients will have multimorbidity during the three waves and can experience a continuing adverse effect on their physical health, which may cause respondents with multimorbidity to maintain low CES-D10 scores. Several studies have shown evidence that physical disability will adversely affect the patient's health level, which further affects the patient's mental health [41]. Moreover, respondents with physical disability face difficulty to completely recover, similar to those with a chronic disease. Hence, respondents 


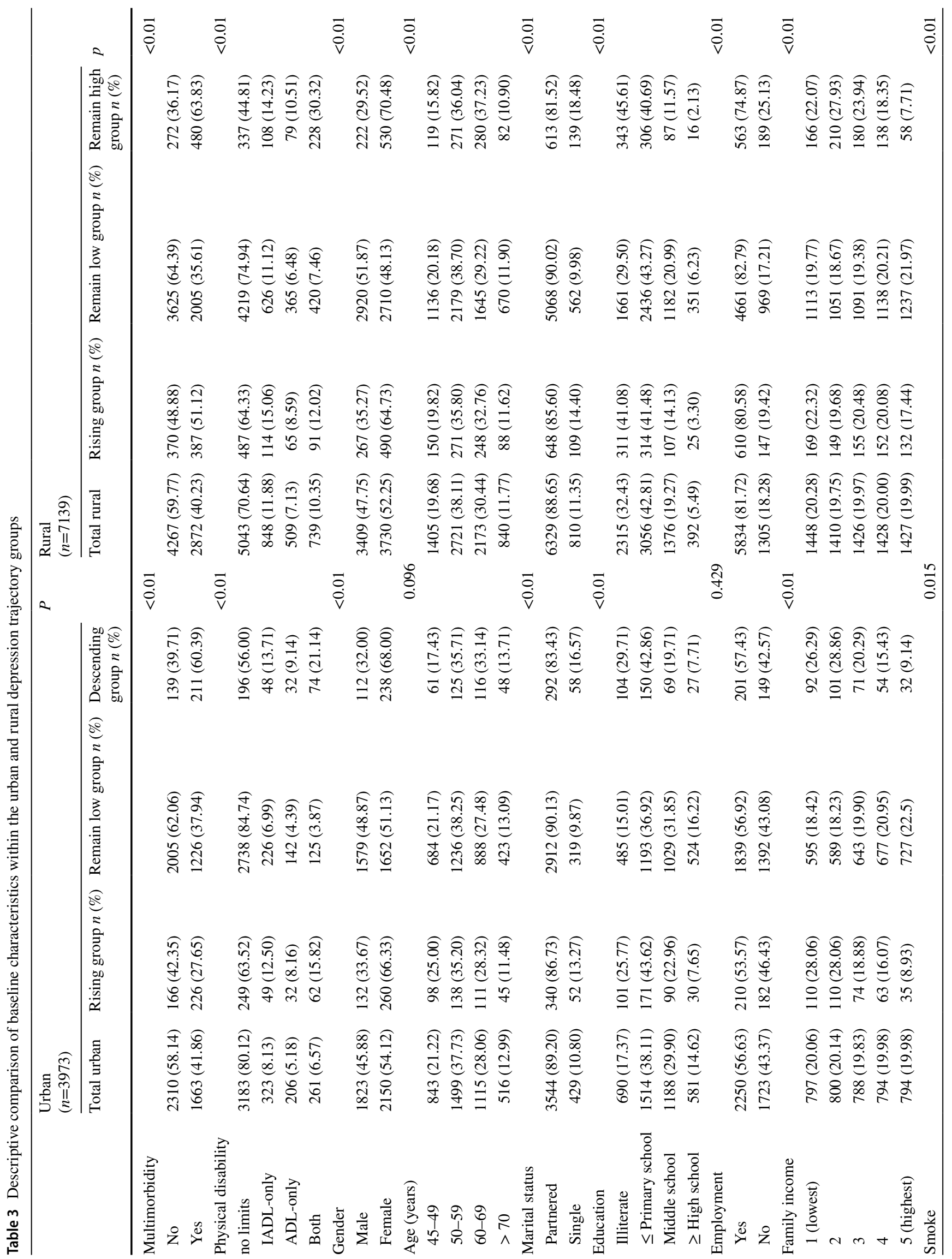




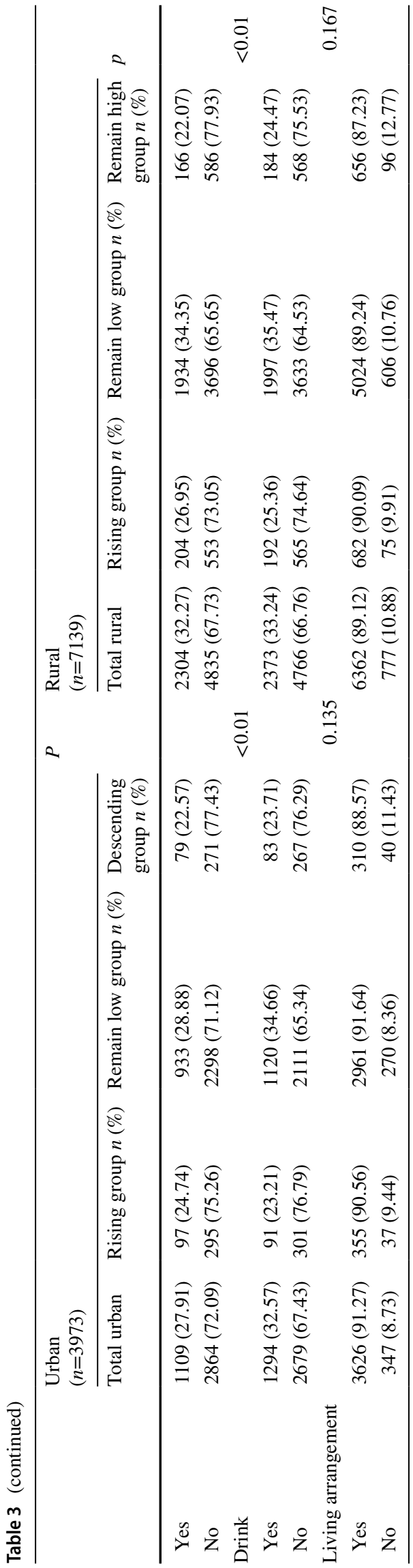

with disabilities with extremely low CES-D10 scores at baseline may rise eventually. No difference was recorded between urban and rural areas with regard to the increase in depressive symptoms, which indicates that the association of multimorbidity and depression trajectories is universal and non-specific.

The long-term uneven distribution of social resources in urban and rural areas may explain that the depression scores of rural patients with multimorbidity remain high, and the older ones in urban areas maintain a low or downward depression scores. With regard to health resources, although China's rural medical system has been greatly improved, a large gap still exists in the allocation of medical resources between urban and rural residents. The number of health technicians per 1000 individuals in urban and rural China was 7.15 and 4.15 in 2009, respectively, and the values totalled 10.91 and 4.63 in 2018. The number of hospital beds per 1000 individuals in urban and rural areas was 5.94 and 2.60 in 2010 and 8.70 and 4.56 in 2018, respectively $[42,43]$. In the long run, the distribution of healthcare resources between urban and rural areas will become more unbalanced. On the other hand, the average reimbursement rate of health insurance for rural residents is lower than that for urban residents, and rural residents encounter higher out-of-pocket costs, which limits the access of rural residents to mental healthcare services [44]. The long-term uneven distribution of healthcare resources and the differences in compensation ratio between urban and rural medical insurance are likely responsible for the additional obstacles encountered by rural patients in accessing quality medical services. This condition may cause the CES-D10 scores of rural patients with multimorbidity to increase for a prolonged period. As for other social benefits, many cities have implemented social benefits for the elderly population, such as free bus rides and regular free medical examinations [22]. This situation may ease the life of urban elderly and may cause the CES-D10 scores of the elderly population in urban areas to remain low and decline.

The difference in social participation between urban and rural areas may lead to an abnormal result of this study, that is, the CES-D10 scores of respondents needing help in ADL and IADL in urban areas were more likely to decline, whereas those of respondents in rural areas were more likely to remain high. Compared with rural areas, urban areas are more likely to provide standardised and high-quality care services for disabled individuals, which alleviates the physical and psychological pain caused by severe disability to a certain extent [45]. Moreover, urban recreational activities are more abundant, whereas rural recreational activities are relatively fewer and are of a gambling nature [46, 47]. This condition may provide disabled patients in urban areas with more opportunities for positive and beneficial social participation and thereby lift their spirit. 
Table 4 Multinomial logistic regression analysis between independent variables of baseline and depression trajectory groups within urban and rural areas, respectively

\begin{tabular}{|c|c|c|c|c|}
\hline & \multicolumn{2}{|l|}{ Urban } & \multicolumn{2}{|l|}{ Rural } \\
\hline & $\begin{array}{l}\text { Remaining low vs. rising } \\
\text { group (RRR) }\end{array}$ & $\begin{array}{l}\text { Declining vs. rising group } \\
\text { (RRR) }\end{array}$ & $\begin{array}{l}\text { Remaining low vs. rising } \\
\text { group RRR) }\end{array}$ & $\begin{array}{l}\text { Remaining high vs } \\
\text { rising group(RRR) }\end{array}$ \\
\hline Multimorbidity (ref: no) & $\begin{array}{l}0.511 * * * \\
(0.408,0.641)\end{array}$ & $\begin{array}{l}1.068 \\
(0.787,1.449)\end{array}$ & $\begin{array}{l}0.565 * * * \\
(0.482,0.661)\end{array}$ & $\begin{array}{l}1.419 * * * \\
(1.147,1.757)\end{array}$ \\
\hline \multicolumn{5}{|c|}{ Physical disability (ref: No limits) } \\
\hline Only IADL & $\begin{array}{l}0.547 * * * \\
(0.386,0.774)\end{array}$ & $\begin{array}{l}1.243 \\
(0.794,1.946)\end{array}$ & $\begin{array}{l}0.744 * * \\
(0.593,0.933)\end{array}$ & $\begin{array}{l}1.256 \\
(0.928,1.700)\end{array}$ \\
\hline Only ADL & $\begin{array}{l}0.515 * * * \\
(0.339,0.782)\end{array}$ & $\begin{array}{l}1.245 \\
(0.731,2.119)\end{array}$ & $\begin{array}{l}0.758^{*} \\
(0.569,1.010)\end{array}$ & $\begin{array}{l}1.554 * * \\
(1.081,2.232)\end{array}$ \\
\hline Both & $\begin{array}{l}0.269^{* * *} \\
(0.189,0.383)\end{array}$ & $\begin{array}{l}1.498^{*} \\
(0.994,2.259)\end{array}$ & $\begin{array}{l}0.685^{* * *} \\
(0.529,0.888)\end{array}$ & $\begin{array}{l}3.087 * * * \\
(2.296,4.151)\end{array}$ \\
\hline Gender (ref: male) & $\begin{array}{l}0.637 * * * \\
(0.470,0.863)\end{array}$ & $\begin{array}{l}1.078 \\
(0.716,1.624)\end{array}$ & $\begin{array}{l}0.578 * * * \\
(0.462,0.722)\end{array}$ & $\begin{array}{l}1.228 \\
(0.908,1.660)\end{array}$ \\
\hline \multicolumn{5}{|l|}{ Age (years, ref: 45-49) } \\
\hline $50-59$ & $\begin{array}{l}1.496 * * * \\
(1.120,1.999)\end{array}$ & $\begin{array}{l}1.480 * \\
(0.985,2.223)\end{array}$ & $\begin{array}{l}1.157 \\
(0.931,1.440)\end{array}$ & $\begin{array}{l}1.094 \\
(0.809,1.480)\end{array}$ \\
\hline $60-69$ & $\begin{array}{l}1.694 * * * \\
(1.238,2.317)\end{array}$ & $\begin{array}{l}1.748 * * \\
(1.139,2.683)\end{array}$ & $\begin{array}{l}1.028 \\
(0.818,1.291)\end{array}$ & $\begin{array}{l}1.061 \\
(0.777,1.447)\end{array}$ \\
\hline$\geq 70$ & $\begin{array}{l}2.154 * * * \\
(1.424,3.257)\end{array}$ & $\begin{array}{l}1.768 * * \\
(1.017,3.076)\end{array}$ & $\begin{array}{l}1.254 \\
(0.928,1.694)\end{array}$ & $\begin{array}{l}0.769 \\
(0.513,1.185)\end{array}$ \\
\hline Marital status (ref: yes) & $\begin{array}{l}1.018 \\
(0.726,1.429)\end{array}$ & $\begin{array}{l}1.274 \\
(0.832,1.950)\end{array}$ & $\begin{array}{l}0.739 * * \\
(0.584,0.935)\end{array}$ & $\begin{array}{l}1.135 \\
(0.847,1.521)\end{array}$ \\
\hline \multicolumn{5}{|l|}{ Education (ref: illiterate) } \\
\hline Primary school & $\begin{array}{l}1.133 \\
(0.845,1.518)\end{array}$ & $\begin{array}{l}0.936 \\
(0.644,1.361)\end{array}$ & $\begin{array}{l}1.224 * * \\
(1.021,1.467)\end{array}$ & $\begin{array}{l}1.026 \\
(0.809,1.301)\end{array}$ \\
\hline Junior school & $\begin{array}{l}1.571 * * * \\
(1.114,2.215)\end{array}$ & $\begin{array}{l}0.879 \\
(0.554,1.393)\end{array}$ & $\begin{array}{l}1.463 * * * \\
(1.134,1.887)\end{array}$ & $\begin{array}{l}1.093 \\
(0.768,1.555)\end{array}$ \\
\hline Senior school and above & $\begin{array}{l}2.023 * * \\
(1.269,3.225)\end{array}$ & $\begin{array}{l}1.031 \\
(0.548,1.943)\end{array}$ & $\begin{array}{l}1.730 * * \\
(1.112,2.690)\end{array}$ & $\begin{array}{l}0.930 \\
(0.477,1.813)\end{array}$ \\
\hline Employment (ref: yes) & $\begin{array}{l}1.021 \\
(0.806,1.293)\end{array}$ & $\begin{array}{l}0.720 * * \\
(0.524,0.988)\end{array}$ & $\begin{array}{l}1.181 \\
(0.959,1.456)\end{array}$ & $\begin{array}{l}1.056 \\
(0.810,1.378)\end{array}$ \\
\hline \multicolumn{5}{|l|}{ Family income (ref: lowest) } \\
\hline 2 & $\begin{array}{l}0.999 \\
(0.740,1.348)\end{array}$ & $\begin{array}{l}1.096 \\
(0.740,1.622)\end{array}$ & $\begin{array}{l}1.066 \\
(0.839,1.356)\end{array}$ & $\begin{array}{l}1.454 * * \\
(1.070,1.974)\end{array}$ \\
\hline 3 & $\begin{array}{l}1.383^{*} \\
(0.996,1.921)\end{array}$ & $\begin{array}{l}1.293 \\
(0.835,2.002)\end{array}$ & $\begin{array}{l}1.024 \\
(0.807,1.301)\end{array}$ & $\begin{array}{l}1.225 \\
(0.898,1.672)\end{array}$ \\
\hline 4 & $\begin{array}{l}1.451 * * \\
(1.024,2.056)\end{array}$ & $\begin{array}{l}1.223 \\
(0.758,1.972)\end{array}$ & $\begin{array}{l}1.005 \\
(0.789,1.280)\end{array}$ & $\begin{array}{l}1.061 \\
(0.767,1.468)\end{array}$ \\
\hline 5 (highest) & $\begin{array}{l}2.633^{* * *} \\
(1.734,3.998)\end{array}$ & $\begin{array}{l}1.339 \\
(0.751,2.388)\end{array}$ & $\begin{array}{l}1.186 \\
(0.921,1.528)\end{array}$ & $\begin{array}{l}0.545 * * * \\
(0.369,0.804)\end{array}$ \\
\hline Smoke (ref: yes) & $\begin{array}{l}1.334 * \\
(0.982,1.811)\end{array}$ & $\begin{array}{l}1.127 \\
(0.745,1.704)\end{array}$ & $\begin{array}{l}1.176 \\
(0.944,1.465)\end{array}$ & $\begin{array}{l}1.146 \\
(0.848,1.548)\end{array}$ \\
\hline Drink (ref: yes) & $\begin{array}{l}0.764 * \\
(0.571,1.022)\end{array}$ & $\begin{array}{l}0.889 \\
(0.600,1.317)\end{array}$ & $\begin{array}{l}0.838^{*} \\
(0.688,1.021)\end{array}$ & $\begin{array}{l}0.856 \\
(0.656,1.118)\end{array}$ \\
\hline \multirow[t]{2}{*}{$\begin{array}{l}\text { Living arrangement } \\
\text { (ref: yes) }\end{array}$} & 0.825 & 1.258 & 1.074 & 1.231 \\
\hline & $(0.567,1.200)$ & $(0.780,2.028)$ & $(0.830,1.390)$ & $(0.887,1.710)$ \\
\hline Cons & $\begin{array}{l}25.245 * * * \\
(9.977,63.877)\end{array}$ & $\begin{array}{l}0.372 \\
(0.107,1.296)\end{array}$ & $\begin{array}{l}34.8085^{* * * *} \\
(17.422,69.546)\end{array}$ & $\begin{array}{l}0.177 * * * \\
(0.069,0.449)\end{array}$ \\
\hline $\begin{array}{l}\text { Obs } \\
\text { Pseudo } R^{2}\end{array}$ & $\begin{array}{l}3973 \\
0.097\end{array}$ & & $\begin{array}{l}7139 \\
0.085\end{array}$ & \\
\hline
\end{tabular}


Table 4 (continued)

95\% confidence interval are indicated within parenthesis

$* * * p<0.01, * * p<0.05, * p<0.1$

Urban and rural women generally participate in the social division of labour, which may be the reason why there is no difference in the depression locus between urban and rural women. The Chinese government has implemented the sunshine project and held many "women's schools" to improve the quality of the female labour force [48]. All these measures have promoted women's employment, especially in rural areas. Extensive employment may make urban and rural women face less different social environment, which may have a similar impact on women's mental health.

The environmental conditions of social participation-social networks are also different, and such situation may be an underlying factor that prompts depression scores to rise in rural respondents without spouses. The social networks of urban residents have contact with people from different backgrounds with weak ties, but the degree of intimacy is low. However, the traditional kinship and neighbourhood relationship are still the main social relations in rural China. The social network among rural residents is limited but strong and stable $[49,50]$. As a result, information that a certain individual lacks a spouse may spread fast and become a part of public awareness for a long time within the rural social networks and be perceived negatively. Hence, the social network in a countryside maybe likely less friendly toward individuals without a spouse.

The specific job types of social participation may lead to urban-rural differences in the relationship between education level and depression trajectory. Unlike individuals in rural areas, who are mainly engaged in agriculture and manual labour, a higher proportion of individuals in urban areas are engaged in intellectual activities [51] indicating the demand for a higher education level. An individual with primary school education level only may face difficulties in finding a secure and comfortable life in the city. Hence, individuals with primary school education can maintain a low CES-D10 scores only in rural areas.

\section{Limitations}

Firstly, prior to obtaining baseline measurements, reliable data regarding a respondent's early history of depression remained unavailable. Therefore, given the limited data, our study only included the result of three waves. Longer longitudinal studies can be conducted when data become available in the future.

Secondly, chronic diseases are self-reported, which results in the underestimation of their association with depression trajectory. The data on chronic diseases were obtained from respondents through a self-reported questionnaire, but no objective medical records were used. Self-reported data may cause underestimation of research results.

Moreover, this study mainly included a family survey and excluded high-risk groups, such as those who were hospitalised with major physical diseases and were unable to recover. However, this condition also suggests that the results obtained were relatively robust.

\section{Conclusions}

The trajectories of depression are different in urban and rural China. Multimorbidity, physical disability, age, marital status and education level have different relationships with the development of depression in urban and rural areas and quality of life. The uneven allocation of resources in urban and rural areas and social participation of respondents may be potential factors. The quality of life should be improved for those with multimorbidity and disabilities by enhancing the level and quality of medical and nursing services to control depression dynamically for a long-term. The allocation of resources needs changes to keep the balance between rural and urban areas. Integrating urban and rural welfare systems (medical insurance, disability care and medical assistance) can be one of the targets. Social participation, especially for the rural elderly, must be promoted by holding recreational activities in rural areas.

Author contributions $\mathrm{CY}$ conceived the idea and wrote the manuscript. HL, YM and QX provided suggestions for the discussion of the manuscript. JW critically revised the paper. The author(s) read and approved the final manuscript.

Funding The research was supported by (1) National Natural Science Foundation of China (71673093); (2) National Natural Science Foundation of China (72074086); (3) Humanities and Social Sciences of Ministry of Education Planning Fund (16YJA840013).

Data availability Our dataset is available on http://charls.pku.edu.cn/ zh-CN/page/data/harmonized_charls.

Code availability The code used and/or analysed during the current study are available from the corresponding author on reasonable request. 


\section{Declarations}

Conflict of interest All authors declare that there is no conflict of interest.

Ethical approval Ethical approval for data collection in CHARLS was obtained from the Biomedical Ethics Review Committee of Peking University (IRB00001052-11015).

Consent to participate All interviewees gave written informed consent before recruitment to the study.

Open Access This article is licensed under a Creative Commons Attribution 4.0 International License, which permits use, sharing, adaptation, distribution and reproduction in any medium or format, as long as you give appropriate credit to the original author(s) and the source, provide a link to the Creative Commons licence, and indicate if changes were made. The images or other third party material in this article are included in the article's Creative Commons licence, unless indicated otherwise in a credit line to the material. If material is not included in the article's Creative Commons licence and your intended use is not permitted by statutory regulation or exceeds the permitted use, you will need to obtain permission directly from the copyright holder. To view a copy of this licence, visit http://creativecommons.org/licenses/by/4.0/.

\section{References}

1. GBD 2017 DALYs and HALE Collaborators. (2018). Global, regional, and national disability-adjusted life-years (DALYs) for 359 diseases and injuries and healthy life expectancy (HALE) for 195 countries and territories, 1990-2017: A systematic analysis for the Global Burden of Disease Study 2017. The Lancet, 392(10159), 1859-1922. https://doi.org/10.1016/s0140 -6736(18)32335-3.

2. Depression (2019). Retrieved September 20, 2020 from https:// www.who.int/news-room/fact-sheets/detail/depression

3. Gu, L., Xie, J., Long, J., Chen, Q., Chen, Q., Pan, R., Yan, Y., Wu, G., Liang, B., Tan, J., Xie, X., Wei, B., \& Su, L. (2013). Epidemiology of major depressive disorder in mainland china: A systematic review. PloS One, 8(6), e65356. https://doi.org/10.1371/ journal.pone.0065356.

4. Li, D., Zhang, D. J., Shao, J. J., Qi, X. D., \& Tian, L. (2014). A meta-analysis of the prevalence of depressive symptoms in Chinese older adults. Archives of Gerontology and Geriatrics, 58(1), 1-9. https://doi.org/10.1016/j.archger.2013.07.016

5. Xue, Z., Wang, Y., Wang, L., Shen, L., Zhang, A., Pan, P., Wang, H., Dou, J., Guo, X., Lv, Y., Jin, L., \& Yao, Y. (2019). Analysis of influencing factors of poststroke depression: Is higher Body Mass Index always a risk factor of poststroke depression? The Journal of Nervous and Mental Disease, 207(3), 203-208. https ://doi.org/10.1097/NMD.0000000000000949.

6. Opie, R. S., Itsiopoulos, C., Parletta, N., Sanchez-Villegas, A., Akbaraly, T. N., Ruusunen, A., \& Jacka, F. N. (2017). Dietary recommendations for the prevention of depression. Nutritional Neuroscience, 20(3), 161-171. https://doi.org/10.1179/14768 30515Y.0000000043.

7. Pastoor, D., \& Gobburu, J. (2014). Clinical pharmacology review of escitalopram for the treatment of depression. Expert Opinion on Drug Metabolism \& Toxicology, 10(1), 121-128. https://doi. org/10.1517/17425255.2014.863873

8. Cuijpers, P., Quero, S., Dowrick, C., \& Arroll, B. (2019). Psychological treatment of depression in primary care: Recent developments. Current Psychiatry Reports, 21(12), 129. https:// doi.org/10.1007/s11920-019-1117-x

9. Greenberg, P. E., Fournier, A. A., Sisitsky, T., Pike, C. T., \& Kessler, R. C. (2015). The economic burden of adults with major depressive disorder in the United States (2005 and 2010). Journal of Clinical Psychiatry, 76(2), 155-162. https://doi.org/10.4088/ JCP. $14 \mathrm{~m} 09298$

10. Afridi, F., Li, S. X., \& Ren, Y. (2015). Social identity and inequality: The impact of China's hukou system. Journal of Public Economics, 123, 17-29. https://doi.org/10.1016/j.jpube co.2014.12.011

11. Guo, J., Liu, C., Wang, X., Qu, Z., Zhang, W., \& Zhang, X. (2017). Relationships between depression, pain and sleep quality with doctor visits among community-based adults in northwest China. Public Health, 147, 30-38. https://doi.org/10.1016/j. puhe.2017.01.031

12. Zhang, Z., \& Wu, X. (2017). Occupational segregation and earnings inequality: Rural migrants and local workers in urban China. Social Science Research, 61, 57-74. https://doi.org/10.1016/j. ssresearch.2016.06.020

13. China Statistical Yearbook (2021). Retrieved January 31, 2021 http://www.stats.gov.cn/tjsj/ndsj/2019/indexch.htm

14. Jin, Y., Li, Z., \& An, J. (2020). Impact of education on Chinese urban and rural subjective well-being. Children and Youth Services Review. https://doi.org/10.1016/j.childyouth.2020.105505

15. Liu, Q., He, H., Yang, J., Feng, X., Zhao, F., \& Lyu, J. (2020). Changes in the global burden of depression from 1990 to 2017: Findings from the Global Burden of Disease study. Journal of Psychiatric Research, 126, 134-140. https://doi.org/10.1016/j. jpsychires.2019.08.002

16. Ren, X., Yu, S., Dong, W., Yin, P., Xu, X., \& Zhou, M. (2020). Burden of depression in China, 1990-2017: Findings from the global burden of disease study 2017. Journal of Affective Disorders, 268, 95-101. https://doi.org/10.1016/j.jad.2020.03.011

17. Charlson, F. J., Baxter, A. J., Cheng, H. G., Shidhaye, R., \& Whiteford, H. A. (2016). The burden of mental, neurological, and substance use disorders in China and India: A systematic analysis of community representative epidemiological studies. The Lancet, 388(10042), 376-389. https://doi.org/10.1016/s0140 -6736(16)30590-6

18. Saunders, R., Buckman, J. E. J., Cape, J., Fearon, P., Leibowitz, J., \& Pilling, S. (2019). Trajectories of depression and anxiety symptom change during psychological therapy. Journal of Affective Disorders, 249, 327-335. https://doi.org/10.1016/j. jad.2019.02.043

19. Leung, J., Fan, V. S., \& Mahadevan, R. (2020). How do different chronic condition comorbidities affect changes in depressive symptoms of middle aged and older adults? Journal of Affective Disorders, 272, 46-49. https://doi.org/10.1016/j.jad.2020.03.125

20. Zhang, L., Xu, Y., Nie, H., Zhang, Y., \& Wu, Y. (2012). The prevalence of depressive symptoms among the older in China: A meta-analysis. International Journal of Geriatric Psychiatry, 27(9), 900-906. https://doi.org/10.1002/gps.2821

21. Huo, X., Gao, Q., Zhai, F., \& Lin, M. (2020). Effects of welfare entry and exit on adolescent mental health: Evidence from panel data in China. Social Science and Medicine, 253, 112969. https:// doi.org/10.1016/j.socscimed.2020.112969

22. Liu, D., Xi, J., Hall, B. J., Fu, M., Zhang, B., Guo, J., \& Feng, X. (2020). Attitudes toward aging, social support and depression among older adults: Difference by urban and rural areas in China. Journal of Affective Disorders, 274, 85-92. https://doi. org/10.1016/j.jad.2020.05.052.

23. Chen, Y., Yin, Z., \& Xie, Q. (2014). Suggestions to ameliorate the inequity in urban/rural allocation of healthcare resources in China. International Journal for Equity in Health, 13(1), 34. https://doi. org/10.1186/1475-9276-13-34 
24. You, L., Yu, Z., Zhang, X., Wu, M., Lin, S., Zhu, Y., Xu, Z., Lu, J., Wei, F., Tang, M., Wang, J., Jin, M., \& Chen, K. (2019). Association between multimorbidity and depressive symptom among community-dwelling elders in Eastern China. Clinical Interventions in Aging, 14, 2273-2280. https://doi.org/10.2147/CIA.S2219 17.

25. Liljas, A. E. M., Jones, A., Cadar, D., Steptoe, A., \& Lassale, C. (2020). Association of multisensory impairment with quality of life and depression in english older adults. JAMA Otolaryngology Head and Neck Surgery. https://doi.org/10.1001/jamao to. 2019.4470

26. Beck, A. T. (2008). The evolution of the cognitive model of depression and its neurobiological correlates. American Journal of Psychiatry, 165(8), 969-977. https://doi.org/10.1176/appi. ajp.2008.08050721

27. Kessler, R. C., Petukhova, M., Sampson, N. A., Zaslavsky, A. M., $\&$ Wittchen, H. U. (2012). Twelve-month and lifetime prevalence and lifetime morbid risk of anxiety and mood disorders in the United States. International Journal of Methods in Psychiatric Research, 21(3), 169-184. https://doi.org/10.1002/mpr.1359

28. Nosek, M. A., \& Hughes, R. B. (2003). Psychosocial issues of women with physical disabilities: The continuing gender debate. Rehabilitation Counseling Bulletin, 46(4), 224-233. https://doi. org/10.1177/003435520304600403

29. Morowatisharifabad, M. A., Alizadeh, A., Bidaki, R., Jambarsang, S., \& Hosseini-Sharifabad, M. (2020). Prevalence of complicated grief and related factors in elderly individuals in Sabzevar City, Iran. Psychogeriatrics. https://doi.org/10.1111/psyg.12579

30. Bulloch, A. G. M., Williams, J. V. A., Lavorato, D. H., \& Patten, S. B. (2017). The depression and marital status relationship is modified by both age and gender. Journal of Affective Disorders, 223, 65-68. https://doi.org/10.1016/j.jad.2017.06.007

31. Kim, J., \& Park, M. J. (2020). Multilevel effect of neighborhood social cohesion and characteristics on suicidal ideation among Korean Older Adults. Community Mental Health Journal. https ://doi.org/10.1007/s10597-020-00678-5

32. Ogawa, R., Seo, E., Maeno, T., Ito, M., Sanuki, M., \& Maeno, T. (2018). The relationship between long working hours and depression among first-year residents in Japan. BMC Medical Education, 18(1), 50. https://doi.org/10.1186/s12909-018-1171-9

33. Zhang, Y., Liu, Z., Zhang, L., Zhu, P., Wang, X., \& Huang, Y. (2019). Association of living arrangements with depressive symptoms among older adults in China: A cross-sectional study. BMC Public Health, 19(1), 1017. https://doi.org/10.1186/s1288 9-019-7350-8

34. Kim, S. A., Kim, E., Morris, R. G., \& Park, W. S. (2015). Exploring the non-linear relationship between alcohol consumption and depression in an elderly population in Gangneung: The Gangneung Health Study. Yonsei Medical Journal, 56(2), 418-425. https ://doi.org/10.3349/ymj.2015.56.2.418

35. Vaughan, L., Leng, X., La Monte, M. J., Tindle, H. A., Cochrane, B. B., \& Shumaker, S. A. (2016). Functional independence in latelife: Maintaining physical functioning in older adulthood predicts daily life function after age 80. Journals of Gerontology. Series A, Biological Sciences and Medical Sciences, 71(Suppl 1), S79-S86. https://doi.org/10.1093/gerona/glv061

36. Bowling, C. B., Fonarow, G. C., Patel, K., Zhang, Y., Feller, M. A., Sui, X., Blair, S. N., Alagiakrishnan, K., Aban, I. B., Love, T. E., Allman, R. M., \& Ahmed, A. (2012). Impairment of activities of daily living and incident heart failure in community-dwelling older adults. European Journal of Heart Failure, 14(6), 581-587. https://doi.org/10.1093/eurjhf/hfs034.

37. Bauer, D. J., \& Curran, P. J. (2003). Distributional assumptions of growth mixture models: Implications for overextraction of latent trajectory classes. Psychological Methods, 8(3), 338-363. https ://doi.org/10.1037/1082-989X.8.3.338

38. Piumatti, G. (2017). Relations between longitudinal trajectories of subjective financial wellbeing with self-rated health among elderly. Medicina (Kaunas, Lithuania), 53(5), 323-330. https:// doi.org/10.1016/j.medici.2017.09.001

39. Deschenes, S. S., Burns, R. J., \& Schmitz, N. (2018). Trajectories of anxiety symptoms and associations with incident cardiovascular disease in adults with type 2 diabetes. Journal of Psychosomatic Research, 104, 95-100. https://doi.org/10.1016/j.jpsychores .2017.11.015

40. Kanesarajah, J., Waller, M., Whitty, J. A., \& Mishra, G. D. (2018). Multimorbidity and quality of life at mid-life: A systematic review of general population studies. Maturitas, 109, 53-62. https://doi. org/10.1016/j.maturitas.2017.12.004

41. Gobbens, R. J. (2018). Associations of ADL and IADL disability with physical and mental dimensions of quality of life in people aged 75 years and older. PeerJ, 6, e5425. https://doi.org/10.7717/ peerj. 5425

42. China Health Statistics Yearbook (2019). Beijing.

43. China Health Statistics Yearbook (2009). China Union Medical University Press.

44. Xu, J., Wang, J., King, M., Liu, R., Yu, F., Xing, J., Su, L., \& Lu, M. (2018). Rural-urban disparities in the utilization of mental health inpatient services in China: The role of health insurance. International Journal of Health Economics and Management, 18(4), 377-393. https://doi.org/10.1007/s10754-018-9238-z.

45. Zhang, L., Zeng, Y., Wang, L., \& Fang, Y. (2020). Urban-rural differences in long-term care service status and needs among homebased elderly people in China. The International Journal of Environmental Research and Public Health. https://doi.org/10.3390/ ijerph17051701

46. Wang, R., Chen, Z., Zhou, Y., Shen, L., Zhang, Z., \& Wu, X. (2019). Melancholy or mahjong? Diversity, frequency, type, and rural-urban divide of social participation and depression in middle- and old-aged Chinese: A fixed-effects analysis. Social Science and Medicine, 238, 112518. https://doi.org/10.1016/j.socsc imed.2019.112518

47. SteinmÜLler, H. (2011). The moving boundaries of social heat: gambling in rural China. Journal of the Royal Anthropological Institute, 17(2), 263-280. https://doi.org/10.111 1/j.1467-9655.2011.01679.x

48. Gender Equality and Women's Development in China. (2021). Retrieved January 31, 2021 from http://www.scio.gov.cn/zfbps/ ndhf/2015/Document/1449896/1449896.htm

49. Norstrand, J. A., \& Xu, Q. (2012). Social capital and health outcomes among older adults in China: The urban-rural dimension. The Gerontologist, 52(3), 325-334. https://doi.org/10.1093/geron t/gnr072

50. Lin, J., \& Si, S. X. (2010). Can guanxi be a problem? Contexts, ties, and some unfavorable consequences of social capital in China. Asia Pacific Journal of Management, 27(3), 561-581. https ://doi.org/10.1007/s10490-010-9198-4

51. Zeng, Q., \& Zeng, Y. (2018). Eating out and getting fat? A comparative study between urban and rural China. Appetite, 120, 409-415. https://doi.org/10.1016/j.appet.2017.09.027

Publisher's Note Springer Nature remains neutral with regard to jurisdictional claims in published maps and institutional affiliations. 